Gámez-Ceruelo, V. \& Sáez-Rosenkranz, I. (2017). La imagen como documento gráfico visual en la enseñanza de la historia en Educación Primaria en perspectiva comparada. Análisis y propuesta didáctica. Revista Electrónica Interuniversitaria de Formación del Profesorado, 20(2), 127-142.

\title{
La imagen como documento gráfico visual en la enseñanza de la historia en Educación Primaria en perspectiva comparada. Análisis y propuesta didáctica
}

\author{
Virginia Gámez-Ceruelo, Isidora Sáez-Rosenkranz \\ Universidad de Barcelona
}

\section{Resumen}

El desarrollo tecnológico del siglo XXI ha ampliado los estímulos visuales e instala la necesidad de promover una alfabetización visual progresiva. Uno de los soportes más usados en aula y con mayor presencia de imágenes son los libros de texto. Así, este artículo pretende: 1) valorar los aprendizajes promovidos en las actividades de los libros de texto que emplean imágenes en Chile y España y 2) sugerir directrices didácticas para su uso como documento gráfico visual en la enseñanza de las ciencias sociales. Se emplearon dos perspectivas metodológicas, la cualitativa y la comparada. Los resultados indican que existe un creciente desarrollo de facultades de aproximación analítica y crítica a las imágenes en Chile, mientras en Cataluña su desarrollo es muy incipiente.

\section{Palabras clave}

Alfabetización visual; Libros de texto; Chile; Cataluña.

\section{Contacto:}

Virginia Gámez-Ceruelo, virgin.ceru@gmail.com, Passeig de la Vall d'Hebron 171, 08035, Barcelona. Vinculado al proyecto I+D+i 65621 financiado por el Ministerio de Economía y Competitividad. IP: Joaquín Prats Cuevas. 


\title{
The image as documental visual font in the History teaching- learning in Primary School in a comparative approach. Analysis and Didactic proposal
}

\begin{abstract}
Technology development into the XXI Century had has widen visual stimulation. It installs the need on developing a progressive visual literacy. One of the most frequent aids with images employed at classrooms are textbooks. Thus, this article aims at 1) valuing promoted learning on images analysis into textbook's tasks in Chile and Spain and 2) to suggest didactical orientations to its use as graphic documents into social sciences teaching. For the analysis two methodological perspectives were employed, the qualitative and the comparative one. Results show that in both places an increasing analytical and critical use of images is developing, but narrower in Catalonia than in Chile.
\end{abstract}

\section{Key words}

Visual literacy; Textbook; Chile; Catalonia.

\section{Introducción}

El desarrollo de la tecnología en el siglo XXI que ha ampliado los estímulos visuales instala la necesidad de promover una alfabetización visual progresiva (Gómez del Águila \& VaqueroCañestro, 2014), las cuales en el área de ciencias sociales debiesen concebirse como documentos gráficos. En esta línea es necesario introducir herramientas para que el alumnado adquiera un desarrollo óptimo en la utilización de las imágenes, lo que directamente implica una correcta alfabetización visual. En este sentido, este texto tiene dos objetivos centrales. En primer lugar, valorar los aprendizajes promovidos en las actividades de los libros de texto (LT) que emplean imágenes en Chile y España. En segundo lugar, sugerir directrices didácticas para su uso como documento gráfico visual en la enseñanza de las ciencias sociales en primaria.

Dentro del área de ciencias sociales de Educación Primaria debemos acercarnos a un uso responsable de la imagen, que conlleva asociado un cambio de perspectiva que permita al estudiantado adquierir un visión crítica de ellas. Aquí, el desarrollo de los contenidos del área de ciencias sociales juegan un rol fundamental, ya que estas buscan promover una aproximación crítica a los fenómenos sociales y la comprensión del presente (Prats, 2011). Concordamos con la idea de que en edades tempranas se puede desarrollar la alfabetización visual en los estudiantes y que ello incide en la formación del pensamiento histórico (Cooper, 2015). La alfabetización visual en primaria es un punto de partida para la adquisición de herramientas de lectura crítica para el posterior aprendizaje de los estudiantes.

En este trabajo, nos centraremos en las imágenes de los LT, puesto que continúa siendo uno de los soportes con presencia de imágenes más usados en el aula, los cuales promueven, además, aprendizajes en sus actividades. Investigaciones recientes señalan que las imágenes no son significativas en el desarrollo de aprendizajes complejos en España (Gámez Ceruelo, 2016; Gómez Carrasco \& López Martínez, 2014) o en Chile (Sáez 
Rosenkranz, 2016). En ambas realidades quedan relegadas más bien a un rol ilustrativo o descriptivo, lo cual se sitúa como un impedimento para adoptar lecturas complejas de las imágenes. En este sentido, su tratamiento como fuente documental favorece el desarrollo del espíritu crítico al tiempo que desarrolla el pensamiento histórico.

Mediante la promoción del pensamiento histórico los estudiantes adquieren competencias y habilidades para enfrentar con una actitud crítica su realidad (Carretero \& Montanero, 2008), lo cual es especialmente significativo en un entorno altamente visual. De esta manera, propender a una adecuada alfabetización visual contribuiría a una aprehensión más crítica de su entorno (Desai, Hamlin \& Mattson, 2010; Gómez del Águila \& VaqueroCañestro, 2014).

En este sentido, analizar la manera en la cual, desde el aula, se propone el trabajo con imágenes en ciencias sociales, puede contribuir a la generación de un diagnóstico que permita establecer orientaciones didácticas necesarias para el desarrollo de una actitud crítica por parte de los estudiantes.

\section{Libros de texto, imágenes y pensamiento histórico}

Los libros de texto son uno de los recursos más frecuentes en aula. Como bien señalaba Valls (2007a), mediante su estudio se puede acceder a una perspectiva amplia sobre cómo se enseña la Historia en el aula. Ellos no sólo presentan los contenidos que se consideran más relevantes desde las directrices institucionales, sino que también producen y reproducen discursos y narrativas respecto a las múltiples dimensiones en las que operan (Martínez Bonafé, 2008).

Como todo producto cultural, los libros de texto, albergan una serie de concepciones y significados (Williams, 1981) que pueden develarse leyendo sus discursos subyacentes (Atienza Cerezo \& Van Dijk, 2010) mediante una aproximación crítica a sus contenidos y narrativas. En esta línea, un acercamiento crítico a la dimensión didáctica de los libros de texto permite develar los significados que operan en sus concepciones. Las acciones llevan implícitas intencionalidades que responden a determinados objetivos y que, a la vez, están en concordancia con las acepciones de significado de un cierto momento histórico (Rogers, 2011).

En el ámbito de la manualística existe una sólida línea de trabajo asociada al trabajo de la imagen, destacando investigaciones sobre su análisis iconológico y las propuestas de la didáctica de la imagen. Estos dos campos se han caracterizado por una mirada interdisciplinar que incluye la Semiótica, la Psicología Educativa y la Comunicación Audiovisual (Kress \& Van Leeuwen, 1996).

En este artículo destacamos la importancia de la cultura visual y el desarrollo de la alfabetización visual en el área de ciencias sociales para complementar la formación global del estudiantado, teniendo en cuenta la perspectiva de los objetivos del área: generar herramientas que permitan el pensamiento histórico y fomentar el pensamiento crítico (Perikleous \& Shemilt, 2011; Prats, 2011; Seixas \& Morton, 2013), el cual debe ser promovido también desde el uso de las imágenes, en este caso, mediante su concepción como documentos. Asumir las imágenes de esta manera conlleva asociada la necesidad de aplicar a su trabajo y análisis los procedimientos propios de la investigación social (Prats \& Santacana, 2011). Esto significa aprehenderlas desde una mirada crítica y no como retratos visuales fehacientes de acontecimientos sociales (Ruiz Berrio, 2007). Por tanto, destacamos la utilidad de la imagen como fuente documental gráfica para el desarrollo de la 
alfabetización visual, permitiendo al estudiantado herramientas para el desarrollo del pensamiento crítico y como recurso para la promoción del pensamiento histórico.

Entendemos el proceso de alfabetización visual como un proceso global de aprehensión crítica de la imagen. Esto implica ir más allá de su descripción como han señalado Moradiellos (2013) y Valls (2007b) recogiendo las categorías de Panofsky. Por tanto, se hace necesario incidir en una formación preiconográfica -o de descripción, técnica y temática-; iconográfica, en la cual se desarrolla un análisis formal y, finalmente iconológica, centrada en la explicación e interpretación de su contenido. Lo anterior adquiere importancia en el contexto actual, puesto que la cultura visual es cada vez más predominante en el ámbito escolar y en los libros de texto. Éstos últimos han aumentado considerablemente en los últimos años su corpus gráfico.

La imagen en el libro de texto de ciencias sociales, tiene abordajes complejos, con diversas caras y focos de interés que pueden ir más allá del análisis de sus mensajes. Uno de los puntos de atención en los que se ha centrado la literatura ha sido la creación de identidades, especialmente, vinculadas a la idea de la historia nacional (Gómez Carrasco \& López Martínez, 2014; López Facal, 2009). Pero pocos estudios se han focalizado en la imagen y su uso didáctico como fuente documental gráfica, el cual entronca con la relación entre imagen e Historia. Así, el empleo de imágenes en el área de ciencias sociales estaría marcado por la concepción de los historiadores sobre la dicotomía entre la objetividad de la imagen como documento fiel del pasado y la polisemia intrínseca a las imágenes (Valls, $2007 b$ ). Sin embargo, en esta investigación, consideramos importante matizar uno de los aspectos que ha sido obviado dentro de la compleja relación que la imagen posee con el área de ciencias sociales: el estudio de las fuentes documentales gráficas es una aportación directa al desarrollo de la alfabetización visual.

Desde este trabajo, reivindicamos el uso de la fuente documental gráfica para un proceso de alfabetización visual gradual, crítico y consciente, no sólo en relación al área de las ciencias sociales, si no como un proceso global y conjunto en el que cada área aporta una perspectiva nueva y acumulativa que ayuda al estudiantado a analizar la complejidad de la imagen, ahondando en aspectos discursivos y de creación de las identidades, complementando otros aspectos cercanos a análisis de la percepción visual.

La didáctica de las ciencias sociales ha apostado por cambiar el enfoque desde la exposición secuencial de contenidos para, mediante la aplicación de una serie de procedimientos y aprendizajes complejos, favorecer una aprehensión crítica de la realidad o el llamado pensamiento histórico (Carretero \& Montanero, 2008).

Estudios recientes en libros de texto en España sugieren que, en términos generales, el pensamiento histórico es escasamente promovido en relación a las actividades (Sáiz Serrano \& Colomer, 2014), y también al uso de las imágenes (Gómez Carrasco \& López Martínez, 2014). En cambio en Chile, recientemente, se han incorporado en gran medida actividades que promueven el pensamiento histórico y un uso crítico de las imágenes (Sáez Rosenkranz, 2016). A diferencia de lo que está ocurriendo en el país sudamericano actualmente, los libros de texto previos a la reforma curricular en curso, también promovían un uso de la imagen ilustrativa (Olivares Felice, 2006).

Consideramos que la presencia secundaria e ilustrativa de la imagen en los libros de texto se encuentra relacionada con la forma en que se ha promovido la enseñanza de la historia, caracterizada por un enfoque secuencial y episódico. Éste ha tenido un calado histórico profundo desde su constitución como materia educativa. Su función estaba relacionada con la construcción de narrativas orientadas a dotar de un espesor histórico a los estados nación (Viñao Frago, 2008). La transmisión de saberes no requería aproximaciones 
analíticas, y en consecuencia, el trabajo con diversos recursos, entre ellos las imágenes, era innecesario. De forma específica, sobre el uso de la imagen en la enseñanza de la historia en libros de texto, la literatura ha señalado que ha sido, y sigue siendo, fundamentalmente ilustrativo (Gámez Ceruelo, 2016), a la vez que refuerza estereotipos acordes a las construcciones que los estado nación han definido (Beniscelli, 2013; Berchenko, 2006). En este sentido, la imagen posee un rol secundario en la formación en ciencias sociales, apoyando, principalmente, su contenido.

Si bien la perspectiva didáctica que promueve aprendizajes analíticos no es nueva, ya que data de los años setenta (Prats, 1989), por diversos motivos (López Facal, 2004) su calado no ha logrado impactar, al menos en los libros de texto como bien lo han demostrado los resultados de las investigaciones recientes (Gómez Carrasco, 2014; Prieto Prieto, Gómez Carrasco, \& Miralles Martínez, 2013; Sáiz Serrano, 2014; Sáiz Serrano \& Colomer, 2014). A pesar de ello, la efectividad de metodologías activas en la enseñanza de la historia que promueven el trabajo con fuentes primarias está constatado (Salazar-Jiménez, BarrigaUbed, \& Ametller-López, 2015).

Reclamamos, por tanto, el papel importante que juega el área de ciencias sociales en el proceso activo de la alfabetización visual. Para ello, hemos puesto atención en el tipo de interacción que se propone entre el estudiantado y las imágenes del libro de texto, de modo que se pueda tener un diagnóstico que permita adquirir progresivamente herramientas para una lectura de las imágenes apropiada mediante su abordaje como fuentes documentales gráficas. Esto permitiría un uso consciente de ellas, más allá del rol ilustrativo que se ha hecho de ellas en los libros de texto.

\section{Metodología}

Para realizar el análisis sobre los aprendizajes promovidos en actividades con imágenes se emplean dos perspectivas metodológicas. Por un lado, la cualitativa en su más amplio sentido (Denzin \& Lincoln, 2005) y, por otro, la perspectiva comparada (Reventós Santamaría, 1983). La primera, permite un análisis en profundidad de cada una de las actividades, mientras la segunda favorece obtener una perspectiva más global sobre el tema.

El análisis cualitativo de los ejercicios con imágenes se ha realizado atendiendo a dos niveles:

- Desarrollo cognitivo (Anderson \& Krathwohl, 2001) y presencia de rasgos del pensamiento histórico (Seixas \& Morton, 2013) de la actividad propuesta.

- Nivel de complejidad en la lectura de la imagen (Moradiellos, 2013; Valls, 2007b).

De esta manera, para realizar un análisis que permitiera discutir el nivel de complejidad de la imagen y de desarrollo cognitivo se construyeron las siguientes categorías analíticas:

- Actividades de complejidad baja: son aquellas actividades de carácter descriptivo, encabezadas por verbos de acción tipo: recordar y entender, en los que las imágenes se emplean para la extracción de información explícita. Los rasgos del pensamiento histórico pueden llegar a situar las imágenes en el tiempo y en el espacio, pero no existe procesamiento de la información que contienen. A nivel de análisis de la imagen, se corresponden con un análisis meramente descriptivo o preiconográfica. 
- Actividades de complejidad moderada: Corresponden a actividades enunciadas por verbos del ámbito de la aplicación y análisis, en las cuales se extrae información no explícita en la imagen. Las actividades presentan una incipiente crítica y análisis de fuentes, pero no logran promover su interpretación. En cuanto al tratamiento de la imagen, se inicia una relación de análisis iconográfico.

- Actividades de alta complejidad: Las actividades de alta complejidad son aquellas que se relacionan con procedimientos de carácter evaluativo o hipotético. Las imágenes son analizadas a interpretadas en su contexto. Corresponden a actividades que las emplean como fuente central de información. Pese a estar en el nivel de Educación Primaria, estas tipología de actividades fomentan el inicio de un desarrollo de un análisis de tipo iconológico.

Estas categorías han permitido incidir en la necesidad de un proceso gradual de la alfabetización visual, incluyendo estos elementos en las pautas de trabajo de las actividades de Educación Primaria en los diferentes ciclos, permitiendo llegar a una mayor complejidad en niveles superiores, como la educación secundaria.

Para el análisis comparativo se aplicaron los procedimientos establecidos por Reventós Santamaría (1983) que corresponden a: descripción, interpretación, yuxtaposición y comparación.

Las actividades con imágenes analizadas son parte de los textos usados en el curso académico 2016 en Chile y 2015/2016 en España para Educación Primaria y su equivalente en Chile, la educación básica. En este último caso, son los textos entregados por el Ministerio de Educación que cubren más del 90\% de la matrícula escolar y, de acuerdo al proceso de compra, provienen de diversas editoriales. Destacamos que las imágenes analizadas en el caso chileno se corresponden con casas editoras de libros de texto españolas.

Se escogieron las actividades más representativas de cada ciclo en cada una de las realidades analizadas'. En España se trabajó con libros de texto de Cataluña y se seleccionaron las dos editoriales más vendidas: editoriales Santillana/Grup Promotor y Vicens Vives, las cuales además poseen una gran popularidad en todo el Estado español.

Para este trabajo, se escogieron seis imágenes por país, dos por ciclo para analizar la progresión. En el caso de España, una por editorial y ciclo. Las actividades analizadas se detalla a continuación:

\footnotetext{
${ }^{1}$ Esta selección fue posible gracias al avance previo realizado en las tesis doctorales de ambas autoras que analizaron en profundidad los textos escolares. También es el resultado ulterior de un primer análisis exploratorio y preliminar censal de las actividades con imágenes en ambos libros de texto en los casos chileno y catalán. Ver: Gámez Ceruelo, 2016, La función educativa de la imagen en el área de Ciencias Sociales de Educación Primaria: Un estudio exploratorio en torno al currículo escolar, los libros de texto y la concepción del alumnado del Grado de Maestro de Educación Primaria y Sáez Rosenkranz, 2016, Análisis de las actividades en libros de texto de Historia, Geografía y Ciencias Sociales de educación básica en Chile.
} 
Tabla 1.

Listado de las actividades analizadas

\begin{tabular}{|c|c|c|c|c|}
\hline \multicolumn{5}{|l|}{ Chile } \\
\hline Curso & $\begin{array}{l}\text { Editorial, } \\
\text { año }\end{array}$ & Unidad & Tema & Instrucción de la actividad ${ }^{2}$ \\
\hline $1^{\circ}$. & $\begin{array}{l}\text { Santillana, } \\
2014\end{array}$ & $\begin{array}{l}\text { 2.Mi } \\
\text { comunidad }\end{array}$ & Mi barrio & $\begin{array}{l}\text { Observa y haz las actividades: a) ¿En qué } \\
\text { lugar están estas personas?; b) ¿Qué } \\
\text { están haciendo?; c) Encierra en un } \\
\text { [imagen de un círculo azul] los que } \\
\text { tienen una mala actitud; d) Encierra en } \\
\text { un [imagen de un círculo rojo] los que } \\
\text { tienen una buena actitud; e) ¿Cómo te } \\
\text { comportas tu en tu barrio? }\end{array}$ \\
\hline $2^{\circ}$. & $\begin{array}{l}\text { Santillana, } \\
2014\end{array}$ & $\begin{array}{l}\text { 3.Chile, una } \\
\text { mezcla de } \\
\text { culturas }\end{array}$ & $\begin{array}{l}\text { Los } \\
\text { inmigrantes } \\
\text { del pasado }\end{array}$ & $\begin{array}{l}\text { ¿Qué características tienen en común las } \\
\text { casas inglesas y las casas que los } \\
\text { inmigrantes ingleses construyeron en } \\
\text { Chile? }\end{array}$ \\
\hline $3^{\circ}$. & $\begin{array}{l}\text { Santillana, } \\
2014\end{array}$ & $\begin{array}{l}\text { 3.Los griegos } \\
\text { de la } \\
\text { antigüedad }\end{array}$ & $\begin{array}{l}\text { Arquitectura } \\
\text { griega }\end{array}$ & $\begin{array}{l}\text { 1) Observa las dos construcciones } \\
\text { chilenas y compáralas con el Partenón. } \\
\text { ¿Crees que hay influencia de los griegos } \\
\text { en nuestras construcciones? ¿Dónde } \\
\text { observas esa influencia?; 2) En tu } \\
\text { localidad, ¿existe algún edificio en el que } \\
\text { se puedan reconocer elementos } \\
\text { arquitectónicos de Grecia? Pega una } \\
\text { imagen de ese edificio en tu cuaderno o } \\
\text { dibújalo. Luego marca los elementos que } \\
\text { heredamos de los griegos. }\end{array}$ \\
\hline $4^{\circ}$. & $\begin{array}{l}\text { Norma, } \\
2015 .\end{array}$ & $\begin{array}{l}\text { 3.Las grandes } \\
\text { civilizaciones } \\
\text { mesoamericana } \\
\text { s }\end{array}$ & Los mayas & $\begin{array}{l}\text { Interpretamos un códice. 1)Observemos } \\
\text { esta imagen del Códice Mendoza (h.1541 } \\
\text { Biblioteca Bodleain, Universidad de } \\
\text { Oxford, Inglaterra); 2)Describamos los } \\
\text { elementos que aparecen en la imagen. 3) } \\
\text { Conclusión: a) ¿qué podemos concluir de } \\
\text { la imagen?; b) ¿Cómo se relaciona la } \\
\text { situación representada en la imagen con } \\
\text { lo que has aprendido? }\end{array}$ \\
\hline $5^{\circ}$. & SM, 2015. & $\begin{array}{lr}4 . & \text { ¿Qué } \\
\text { aspectos de la } \\
\text { sociedad } \\
\text { colonial son } \\
\text { parte de } \\
\text { nuestra } \\
\text { identidad } \\
\text { cultural? }\end{array}$ & $\begin{array}{l}\text { Sociedad } \\
\text { colonial }\end{array}$ & $\begin{array}{l}\text { Observa la imagen, luego responde: a) } \\
\text { Según su contexto de origen, ¿esta } \\
\text { fuente es primaria o secundaria? ¿Por } \\
\text { qué?; b) ¿Qué aspectos de la colonia se } \\
\text { observan representados en esta fuente y } \\
\text { qué intención crees que tuvo el autor } \\
\text { para representar dicho aspecto. Explica. }\end{array}$ \\
\hline $6^{\circ}$. & SM, 2015 & $\begin{array}{l}\text { 5. ¿Porqué la } \\
\text { democracia es } \\
\text { considerada el } \\
\text { mejor sistema } \\
\text { para convivir en } \\
\text { sociedad? }\end{array}$ & Democracia & $\begin{array}{l}\text { 7. ¿Qué diferencias observas en las } \\
\text { fotografías de los docs. } 1,2 \text { y } 3 \text { ? ¿A qué } \\
\text { crees que se deben esas diferencias?; } 8 \text { ) } \\
\text { ¿Qué celebran las multitudes en las } \\
\text { fotografías de los Docs. } 4 \text { a } 7 \text { ? ¿Crees que } \\
\text { son situaciones que merecen una } \\
\text { celebración popular? ¿Por qué? }\end{array}$ \\
\hline
\end{tabular}

\footnotetext{
${ }^{2}$ Las actividades en catalán se han traducido al castellano por las autoras.
} 


\begin{tabular}{|c|c|c|c|c|}
\hline \multicolumn{5}{|c|}{ Cataluña } \\
\hline $1^{\circ}$. & $\begin{array}{l}\text { Grup } \\
\text { Promotor } \\
\text { /Santillana } \\
2011\end{array}$ & $\begin{array}{l}\text { Tema } \\
\text { introductorio. } \\
\text { "iComienzas } \\
\text { primero!" }\end{array}$ & La escuela & $\begin{array}{l}\text { Las personas que trabajan en las escuela. } \\
\text { Relaciona: [imágenes de trabajos en la } \\
\text { escuela con sus nombres en texto: } \\
\text { maestra, director, cocinero, conserje, } \\
\text { secretaria, personal de limpieza] }\end{array}$ \\
\hline $2^{\circ}$. & $\begin{array}{l}\text { Vicens Vives } \\
2015\end{array}$ & $\begin{array}{l}\text { 9. El paso del } \\
\text { tiempo }\end{array}$ & El tiempo & $\begin{array}{l}\text { Fíjate bien en las fotografías y contesta: } \\
\text { ¿Es el mismo lugar? ¿Qué ha cambiado? }\end{array}$ \\
\hline $3^{\circ}$. & $\begin{array}{l}\text { Grup } \\
\text { Promotor } \\
\text { /Santillana } \\
2012\end{array}$ & $\begin{array}{l}\text { 12. Observamos } \\
\text { el paso del } \\
\text { tiempo }\end{array}$ & El tiempo & $\begin{array}{l}\text { A lo largo de la historia se distinguen } \\
\text { diversas épocas: la de las cuevas, la de } \\
\text { los romanos, la de los castillos, la de las } \\
\text { fábricas y la actualidad. } \\
\text { Ordena las imágenes de la más antigua a } \\
\text { la más reciente. } \\
\text { (se incluye la imagen de una pintura } \\
\text { rupestre; un acueducto romano, un } \\
\text { castillo y una fábrica) }\end{array}$ \\
\hline $4^{\circ}$. & $\begin{array}{l}\text { Vicens Vives } \\
2014\end{array}$ & $\begin{array}{l}2 . \quad \text { Paisajes } \\
\text { naturales y } \\
\text { humanizados. }\end{array}$ & $\begin{array}{l}\text { Actividades } \\
\text { de repaso }\end{array}$ & $\begin{array}{l}\text { Observa las imágenes de estos paisajes y } \\
\text { compáralas. a) ¿Qué diferencia } \\
\text { fundamental puedes establecer entre } \\
\text { estos dos paisajes? b) Enumera las } \\
\text { modificaciones que han introducido los } \\
\text { seres humanos al paisaje 2; c) ¿Qué } \\
\text { actividades humanas han promovido la } \\
\text { alteración de estos paisajes?; d) ¿En cuál } \\
\text { de los dos paisajes debe ser más alta la } \\
\text { contaminación? ¿Por qué? }\end{array}$ \\
\hline $5^{\circ}$. & $\begin{array}{l}\text { Grup } \\
\text { Promotor } \\
\text { /Santillana } \\
2009\end{array}$ & $\begin{array}{l}\text { 12. La Edad } \\
\text { Media }\end{array}$ & $\begin{array}{l}\text { Actividades } \\
\text { de evaluación }\end{array}$ & $\begin{array}{l}\text { 4) Fíjate en las imágenes y explica los } \\
\text { pasos que se siguen para imprimir un } \\
\text { libro; 5) ¿Crees que la invención de la } \\
\text { imprenta en el siglo XV supuso para la } \\
\text { difusión de la información lo mismo que } \\
\text { ha significado internet en el siglo XXI? } \\
\text { ¿Por qué? }\end{array}$ \\
\hline $6^{\circ}$. & $\begin{array}{l}\text { Vicens Vives } \\
2011\end{array}$ & $\begin{array}{l}\text { 3. La Edad } \\
\text { Moderna }\end{array}$ & $\begin{array}{l}\text { La difusión } \\
\text { del } \\
\text { Humanismo }\end{array}$ & $\begin{array}{l}\text { 32. Señala dos características que } \\
\text { consideres fundamentales del estilo } \\
\text { románico y dos del estilo gótico; } 33 \text { ) ¿Por } \\
\text { qué las iglesias góticas son más } \\
\text { luminosas que las románicas?; 34) ¿Qué } \\
\text { construcción corresponde al arte } \\
\text { románico y cuál al gótico? ¿Por qué lo } \\
\text { sabes? }\end{array}$ \\
\hline
\end{tabular}

\section{Análisis de resultados}

\section{Las imágenes en libros de texto chilenos}

En el caso chileno, las imágenes escogidas corresponden a cada uno de los cursos de educación básica (figura 1). De primero a tercero básico abordan entornos urbanos, mayoritariamente cercanos al estudiante y tienen relación con su presente. En primero básico se ha escogido una ilustración sobre el barrio; en segundo y tercero, actividades con fotografías: una comparativa de una calle de la ciudad de Valparaíso en relación con una 
calle inglesa contemporánea ${ }^{3}$ en segundo y otra de la arquitectura de estilo grecorromano y de estilo neoclásico en tercero. En primero básico, la instrucción remite a la identificación del comportamiento adecuado y no adecuado en el espacio público, mientras en segundo y tercero, a partir de las fotografías se verifican las similitudes apuntando a la herencia de estas culturas (tabla 1).

Desde cuarto a sexto básico, las imágenes son lejanas al cotidiano de los estudiantes. En cuarto se emplea una ilustración sobre el mensaje de códices mayas. En quinto una pintura de castas mexicana del siglo XVII y en sexto fotografías sobre clases sociales del siglo XX y de celebraciones masivas en eventos políticos (discursos presidenciales, constitución de 1980 y retorno a la democracia). Las instrucciones remiten a metodología de análisis en cuarto y al análisis de las imágenes en los últimos dos cursos (tabla 1).

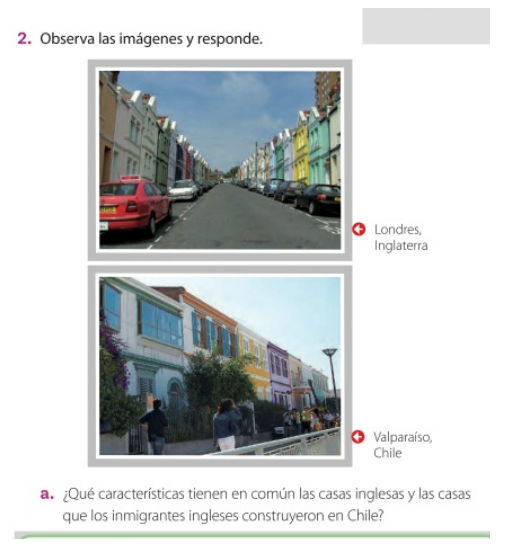

$2^{\circ}$. básico

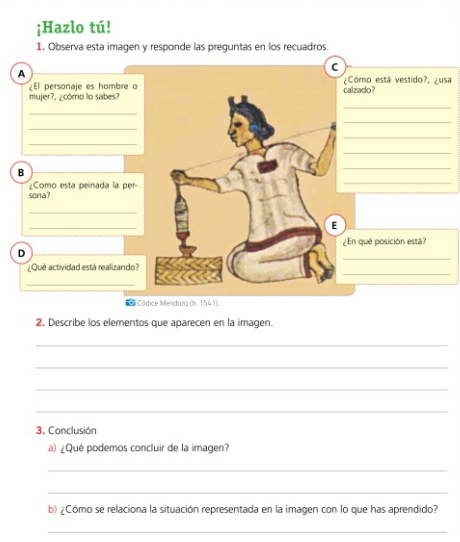

$4^{\circ}$. básico

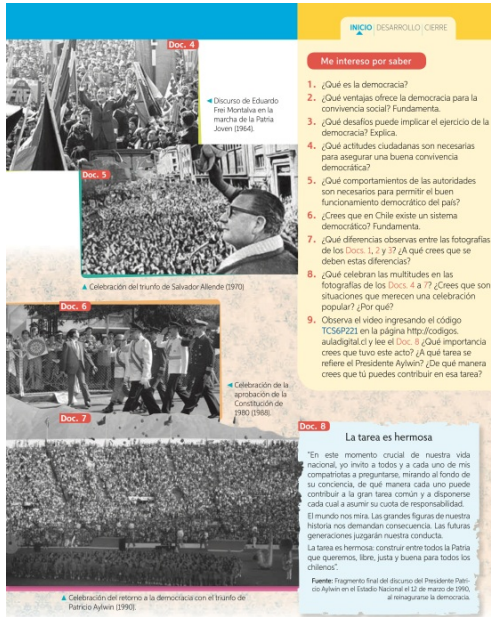

$6^{\circ}$ básico

Figura 1. Ejemplos de imágenes analizadas en libros de texto chilenos

En todas estas actividades las imágenes tienen un rol central, puesto que son el recurso a partir del cual el estudiante construye su conocimiento. Así, en los libros chilenos se evidencia que el papel que juega la imagen tiende a alejarse de la función ilustrativa que han detectado estudios para otras temporalidades (Olivares Felice, 2006).

En lo que corresponde a la dimensión cognitiva, el aprendizaje propuesto a partir del trabajo con imágenes es gradual. Comienza con la identificación de elementos en primero básico; la comparación con elementos dados en segundo; la comparación e interpretación en tercero; la descripción, análisis e interpretación en cuarto; la crítica, observación e interpretación de fuentes en quinto y finalmente, la comparación y valoración de los hechos retratados en sexto.

Esta progresión sugiere que se incluyen gradualmente elementos del uso de la imagen como un documento gráfico visual. Así, se localizan dentro del nivel de complejidad medio y alto. Se entregan herramientas para la descripción global de la imagen y su observación (primero básico), pero también para su comparación y análisis (segundo y tercero básico). El trabajo en concreto como documento gráfico visual se inicia en cuarto básico y se

\footnotetext{
${ }^{3}$ Valparaíso fue una ciudad con gran influencia inglesa durante el siglo XIX y su arquitectura se asemeja a la británica.
} 
consolida en quinto con la crítica e interpretación de las fuentes. En sexto, el trabajo con imágenes se vuelve hacia los niveles comparativos pero se avanza hacia la valoración de los hechos retratados, a modo más bien ilustrativo, sin mediar crítica. Este rasgo, como hemos señalado previamente (Sáez Rosenkranz, 2016), es concordante con el trabajo que se ha dado de la historia del tiempo presente y situaciones conflictivas, el cual tiende a abordar de una forma neutra y poco problematizada los acontecimientos del pasado reciente (Toledo Jofré, Magendzo Kolstrein, Gutiérrez Gianellad, Iglesias Segura, \& López-Facal, 2015). Al margen de lo anterior, se destaca que sexto básico es el curso en el cual el uso de la imagen -como documento gráfico- es menos desarrollado y, en consecuencia, también es minoritario el trabajo del pensamiento histórico ${ }^{4}$.

Por lo tanto, se evidencia que en Chile el uso de la imagen tiende a ser empleado como un documento gráfico visual con una creciente inclusión de rasgos del pensamiento histórico y una progresión de aprendizajes cognitivos.

\section{Las imágenes en libros de texto catalanes}

Al igual que los libros chilenos, la cercanía y complejidad de las imágenes se relacionan con la progresión de los ciclos. Las actividades presentan imágenes con temáticas cercanas al entorno más próximo del estudiantado en ciclo inicial, tales como el colegio, el mercado o el hospital, para ir alejándose progresivamente en el ciclo superior con un mayor número de monumentos o espacios institucionales (figura 2). Sin embargo, la recolección de imágenes, en el caso catalán, ha presentado características más significativas en cuanto a la relación de la imagen con la tipología del ejercicio, destacando que la relación establecida entre los enunciados y la selección de las fotografías potencian la función ilustrativa de la imagen.

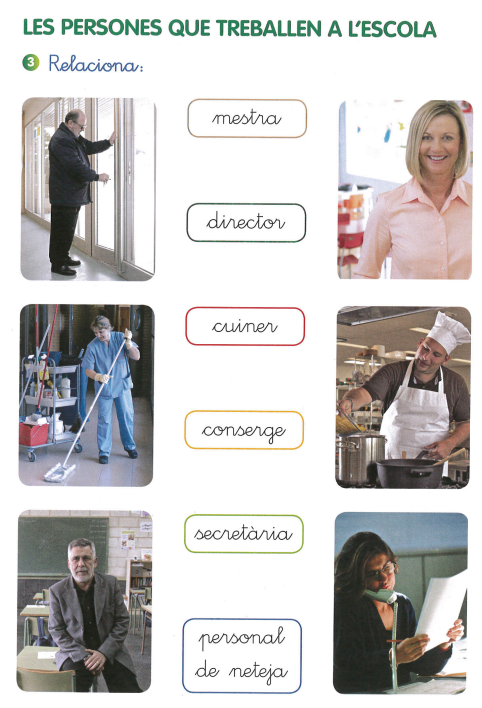

$1^{\circ}$. primaria

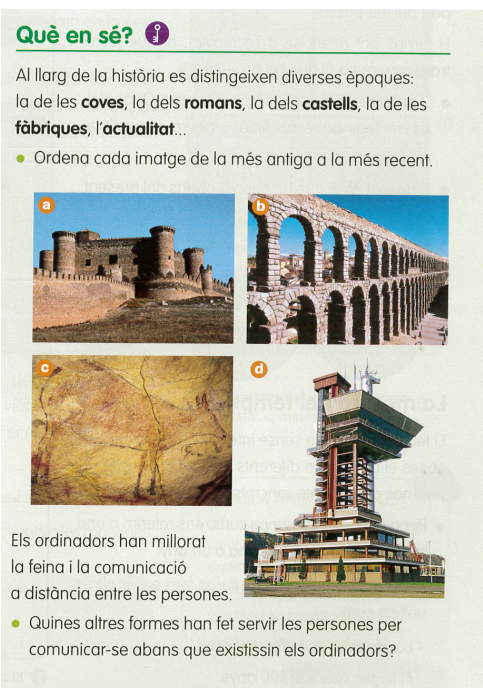

$3^{\circ}$. primaria

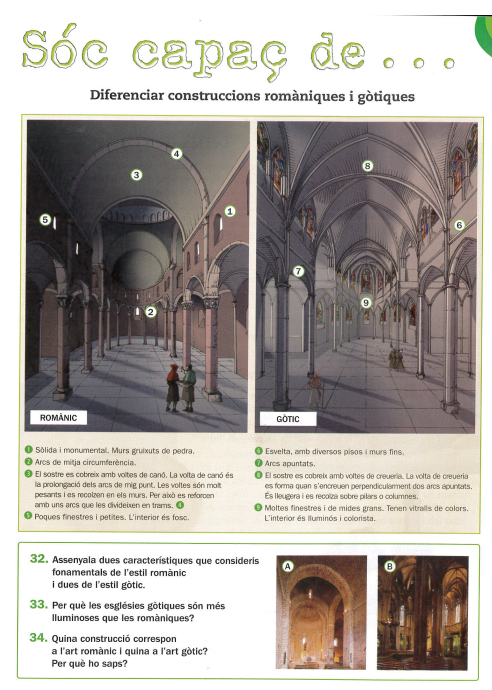

$6^{\circ}$. primaria

Figura 2. Ejemplos de imágenes analizadas en libros de texto catalanes

En el caso de los ejemplos seleccionados en los libros de texto catalanes debemos resaltar que es la relación entre el nivel de desarrollo cognitivo y el nivel de complejidad de las

\footnotetext{
${ }^{4}$ Una análisis más profundo sobre esta temática se puede ver en la tesis doctoral Análisis de las actividades de Historia, Geografía y Ciencias Sociales de educación básica en Chile (Sáez Rosenkranz, 2016).
} 
imágenes seleccionadas lo que ha destacado de forma significativa en el análisis realizado. En primer lugar, si analizamos de manera individualizada el nivel de progresión cognitiva, podría llegar a ser considerado como "correcto" el modo en el que ambas editoriales presentan el tratamiento de las imágenes en las actividades. Esto se debe a que existe un nivel diferenciado de complejidad en cada ciclo, manteniendo actividades que van desde tareas sencillas del ámbito recordar o identificar hasta el ciclo superior en el que se encuentran ejemplos que invitan al estudiantado a analizar e interpretar en su contexto. Se aprecia que se realiza una graduación de la dificultad en las propuestas: en ciclo inicial se proponen actividades como reconocer para el primer curso, en segundo una comparativa que implica analizar el paso del tiempo. En ciclo medio, encontramos en tercero otra línea del tiempo y en cuarto un ejercicio que implica observar y comparar, finalizando en ciclo superior con una imagen en quinto, la cual a priori se podría interpretar como un análisis iconográfico vinculado con un modelo historiográfico más cercano a la historia de la mentalidades $y$, en sexto con un análisis iconográfico de estilos artísticos en el que se potencia el reconocimiento de características formales para diferenciar estilos artísticos. Como se puede apreciar, la orientación propuesta en las actividades sería de gran interés para el aprendizaje del estudiantado.

Sin embargo, este nivel de progresión de la instrucción no se correlaciona con el nivel de complejidad de las imágenes, dificultando, por tanto, el desarrollo de la alfabetización visual del estudiantado de primaria. La selección de imágenes potencia el vínculo textoimagen, afianzando por un lado la función ilustrativa, y por otro, destacando cómo de un modo indirecto se genera una correlación inapropiada entre las órdenes pautadas en el enunciado de la actividad y la dificultad cognitiva que presentan las imágenes. De este modo, acciones como reconocer quedan relegadas a un esfuerzo cognitivo bajo por parte del estudiantado, debido a la conexión establecida entre texto-imagen. La obviedad de la respuesta es tal, que no representa un verdadero reto de aprendizaje, siendo la respuesta dada implícitamente en el ejercicio, potenciando, por tanto, el nivel ilustrativo de la propuesta editorial.

El tipo de propuestas que implican la realización de una comparativa, también se encuentran en este nivel bajo de complejidad cognitiva. Destacamos el caso del ejercicio 4, de cuarto de primaria (figura 3), donde se puede observar la incongruencia entre enunciado y contenido de la imagen. El ejercicio propone al estudiantado una comparativa a partir de una selección de imágenes muy diferenciada, presentando un plano corto y una vista aérea. La pauta del ejercicio manipula y dirige la respuesta del estudiantado, anulando aspectos básicos para una correcta interpretación de la imagen, e imposibilitando análisis más imaginativos y/o críticos. De este modo, la extracción de información sobre estas imágenes, en clave de comparativa, provocaría una lectura de las imágenes sesgada y simplista, haciendo que los alumnos realicen juicios de valor fáciles y precipitados, en lugar de provocar un análisis más complejo. 


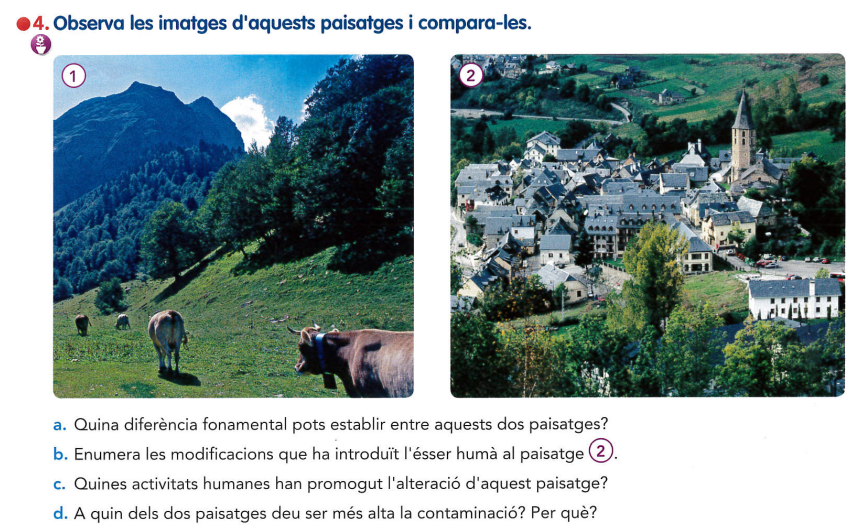

Figura 3. Actividad de $4^{\circ}$. de Educación Primaria

En esta línea, encontramos que, en ciclo superior, la información que debe ser extraída de la lectura y análisis de las imágenes es dada al estudiantado de manera literal en el libro a través del texto escrito. Se señala, por ejemplo, la actividad seleccionada para sexto: Señala dos características que consideres fundamentales del estilo románico y dos del estilo gótico; 33) ¿Por qué las iglesias góticas son más luminosas que las románicas?; 34) ¿Qué construcción corresponde al arte románico y cuál al gótico? ¿Por qué lo sabes?”. En la misma página de la actividad (figura 2), aparecen dos ilustraciones que se corresponden con las imágenes del interior de las iglesias propuestas, pudiendo el alumnado tomarlas como referencia, y en cuyo pie de foto aparece literalmente la información a señalar, pudiendo el estudiantado responder a la pregunta sin necesidad de analizar las imágenes. De esta manera, se potencian los aspectos formalistas de la Historia del Arte, imposibilitando a esta área promover una lectura de imágenes compleja (Gómez del Águila \& Vaquero-Cañestro, 2014), dando herramientas al estudiantado solo en este sentido formalista.

\section{Discusión}

El trabajo con las imágenes en los libros de texto chilenos y catalanes de Educación Primaria indica que la selección de éstas tiende a ser coherente con cada una de las etapas por las cuales transita el estudiante. En ambas realidades son más cercanas al contexto del estudiante en los cursos inferiores y más lejanas en la medida en que van avanzando en los cursos superiores. A su vez, se evidencia que, si bien existe una progresión coherente respecto a las instrucciones plateadas en términos cognitivos, hay una distancia significativa en el rol que las imágenes poseen en la promoción del pensamiento histórico. La función ilustrativa predomina en el caso catalán como bien ya se había señalado en otras investigaciones de libros de texto en esta comunidad autónoma (Gámez Ceruelo, 2016) y también para otras realidades del país (Gómez Carrasco \& López Martínez, 2014). Esta función ilustrativa no es tan clara en los libros de texto chilenos, puesto que las actividades analizadas tienen como base fundamental el trabajo de éstas como fuentes documentales gráficas. La idea de utilizar en aula las imágenes como documento gráfico ha sido defendida desde la didáctica de la historia y las ciencias sociales (Gómez Carrasco \& López Martínez, 2014; Prats, 2011; Valls, 2007b), puesto que su trabajo, aplicando los pasos propios de la investigación social, contribuye a la promoción del pensamiento histórico.

Una dificultad para la promoción del pensamiento histórico mediante el uso de las imágenes como documento gráfico visual es la pertinencia de su selección. Hay una distancia entre las instrucciones con las cuales el estudiante debe realizar las actividades y 
las características de la imagen. En el caso chileno, éstas son coherentes con las instrucciones y permiten desarrollar las tareas a partir de ellas de forma progresiva. Se promueve una lectura crítica que adquiere una complejidad gradual conforme se avanza en los distintos niveles.

La alfabetización visual que requiere un trabajo continuo sobre una lectura crítica de la imagen es, en consecuencia, un rasgo trabajado de forma dispar en ambas realidades. En Chile se promueve con frecuencia, con una complejidad creciente y con pautas claras para su desarrollo, mientras en Cataluña su promoción se ve truncada por la poca pertinencia de las imágenes y la información sesgada que presentan.

Por tanto, al realizar la comparativa entre Chile y Cataluña aplicando los diferentes niveles de análisis, tanto de desarrollo cognitivo como de complejidad de la imagen, podemos afirmar las siguientes ideas en relación al desarrollo de la alfabetización visual y del pensamiento histórico.

Hemos encontrado un gran número de actividades que desarrollan la lectura de imagen desde la extracción de información explícita, de complejidad baja. Para el desarrollo del estudiantado de ciclo inicial es necesario incidir en la utilidad de este tipo de actividades, ya que la alfabetización visual necesita de una progresión paulatina en cuanto a la dificultad de las tareas cognitivas. Sin embargo, cabe considerar, del mismo modo, la necesidad de no caer en una relación texto-imagen simplista que no suponga un reto cognitivo adecuado a su nivel de progresión. Esta idea se puede destacar más en profundidad mediante el análisis de las actividades de complejidad media. Para ello, podemos observar los ejercicios del curso de segundo y tercero básico en Chile, en contraposición con el de cuarto de primaria en Cataluña. La selección de imágenes realizada por la propuesta editorial chilena es acertada en cuanto a la relación del enunciado y la selección de imágenes, permitiendo al estudiantado realizar comparativas entre las imágenes. Sin embargo, la selección de imágenes de la propuesta catalana imposibilita al estudiantado a adquirir herramientas de lectura de imágenes provocando respuestas que no proceden de la obtención de información de las imágenes. El enunciado de las actividades debe ser debidamente reforzado con una selección de imágenes apropiada, posibilitando que el estudiantado pueda trabajar la imagen como una fuente documental gráfica, generando así una base para la formación del pensamiento histórico. Para el logro del desarrollo cognitivo de actividades de nivel alto, la función ilustrativa, potenciada por un excesivo uso del vínculo texto-imagen puede desvirtuar tareas complejas como el análisis de imagen, favoreciendo la mera descripción de imágenes en lugar de acciones más relacionadas con la interpretación.

\section{Conclusiones y orientaciones didácticas}

El estudio permite sostener que existe una diferencia sustancial en el tratamiento de las imágenes en ambas realidades. Mientras en el caso chileno se emplean como documento gráfico, en el catalán tienden a cumplir un rol ilustrativo. Asimismo, en el caso americano su selección y tratamiento didáctico es concordante, mientras en el europeo esta relación no es tan clara.

En el proceso de selección y diseño didáctico es necesario atender a la adecuación del desarrollo cognitivo en las actividades, a la complejidad de la imagen seleccionada y a la relación entre ellas y las instrucciones, ya que en estos elementos radica una alfabetización visual y procedimientos progresivos. 
Si consideramos que son los profesores quienes aplican estos materiales en sus aulas, es de vital relevancia que conozcan los distintos niveles de análisis visual y su trabajo de forma progresiva. Asimismo, es necesario que sean capaces de evaluar la calidad del material gráfico propuesto de cara a detectar y corregir el tipo de aproximación didáctica, para así progresar hacia un análisis iconológico. Aunque este tipo de análisis es más propio de niveles más altos, como la secundaria, para llegar a ello es necesaria una secuenciación gradual desde lo preiconográfico hacia lo iconológico. Por tanto, en Educación Primaria se debería comenzar por tareas sencillas a nivel cognitivo, cuidando el uso excesivo de la función ilustrativa de la imagen y de la introducción de la relación texto-imagen aplicada de un modo simplista.

En síntesis, consideramos relevante que el trabajo con imágenes en Educación Primaria implique una revisión crítica por parte del profesorado; promueva una aproximación gradual y progresiva hacia el análisis iconológico y se aleje de la concepción ilustrativa de la imagen en la enseñanza de las ciencias sociales. En este sentido, destacamos la importancia de la labor de los didactas de cara a la selección y tratamiento educativo de contenidos, en este caso imágenes, para que sean trabajadas como fuentes documentales gráficas.

Como apunte final, cabe destacar que la distancia que observamos en el trabajo de las imágenes en ambas realidades comparten en algunos casos las casas editoriales. En este sentido, vale preguntarse ¿qué otros factores están incidiendo en la promoción o no de una alfabetización visual?

\section{Referencias}

Anderson, L., \& Krathwohl, D. (2001). A Taxonomy for Learning, Teaching, and Assessing: A revision of Bloom's Taxonomy of Educational Objectives. New York: Longman.

Atienza Cerezo, E., \& Van Dijk, T. A. (2010). Identidad social e ideología en libros de texto españoles de Ciencias Sociales. Revista de Educación, 353, 67-106.

Beniscelli, L. (2013). Representaciones visuales de indígenas y suramericanas/os: análisis de la relación imagen-texto en ilustraciones de libros de Ciencias Sociales para Educación General Básica. Chile, 1970-1980. Cuadernos Chilenos de Historia de la Educación, 1(1), 112-145.

Berchenko, P. (2006). Funciones, estereotipos y valores de la imagen en el libro de texto chileno Saber (1982). En J.-L. Guereña (Ed.), Image et transmission des Savoirs dans les Mondes Hispaniques et Hispano-Américains (pp. 505-515). Tours-France: CIREMIA.

Carretero, M., \& Montanero, M. (2008). Enseñanza y aprendizaje de la Historia: aspectos cognitivos y culturales. Cultura y educación, 20(2), 133-142.

Cooper, H. (2015). How Can We Plan for Progression in Primary School History? Revista de Estudios Sociales No.35, 52, 16-31. https://doi.org/10.7440/res52.2015.02

Desai, D., Hamlin, J. \& Mattson, R. (2010). History as Art, Art as History. Contemporary Art and Social Studies Education. New York: Routledge.

Gámez Ceruelo, V. (2016). La función educativa de la imagen en el área de Ciencias Sociales de Educación Primaria: Un estudio exploratorio en torno al currículo escolar, los libros de texto y la concepción del alumnado del Grado de Maestro de Educación Primaria (Tesis doctoral). Universidad de Barcelona, Barcelona. 
Gómez del Águila, L. M., \& Vaquero-Cañestro, C. (2014). Educación Artística y experiencia importada: Cuando la construcción de significados recae en lo anecdótico. Arte, Individuo y Sociedad, 26(3), 387-400.

Gómez Carrasco, C. J. (2014). Pensamiento histórico y contenidos disciplinares en los libros de texto. Un análisis exploratorio de la Edad Moderna en 20 de la ESO. ENSAYOS, Revista de la Facultad de Educación de Albacete, 29, 131-158.

Gómez Carrasco, C. J. y López Martínez, A. M. (2014). Las imágenes de los libros de texto y su función en la enseñanza de la Historia. Diseño de un instrumento de análisis. Enseñanza de las Ciencias Sociales. Revista de Investigación, (13), 17-29.

Kress, G. \& Van Leeuwen, T. (1996). Reading Images: The Grammar of Visual Design. New York: Routledge.

López Facal, R. (2004). El pensamiento crítico debe ser, en primer lugar, autocrítico. Enseñanza de las Ciencias Sociales. Revista de Investigación, (3), 95-101.

López Facal, R. (2009). Identificación e identidad nacional en los manuales de historia españoles. En J. Rodríguez Rodríguez, M. Horsley, \& S. V. Knudsen (Eds.), 10th International Conference on Textbook and Educational Media. Local, National and Transnational Identities in Textbook and Educational Media (pp. 214-239). Santiago de Compostela: IARTEM.

Martínez Bonafé, J. (2008). Los libros de texto como práctica discursiva. Revista de la Asociación de Sociología de la Educación, 1(1), 62-73.

Moradiellos, E. (2013). El oficio de historiador. Estudiar, enseñar, investigar. Madrid: Akal.

Olivares Felice, P. (2006). Rapports «Texte-Image»: Quelques observations concernants des Manuels d'Histoire du Chili. En J.-L. Guereña (Ed.), Image et transmission des Savoirs dans les Mondes Hispaniques et Hispano-Américains (pp. 495-502). Tours-France: CIREMIA.

Perikleous, L., \& Shemilt, D. (Eds.). (2011). The future of the past: why history education matters. Nicosia: Association for Historica Dialogue and Research.

Prats, J. (1989). Las experiencias didácticas como alternativas al cuestionario oficial: reflexiones críticas sobre las experiencias «Germanía-75» e «Historia 13-16». En M. Carretero, Mario, J. I. Pozo, \& M. Asenso (Eds.), La Enseñanza de las Ciencias Sociales (pp. 201-210). Madrid: Visor.

Prats, J. (Ed.). (2011). Didáctica de la Geografía y la Historia. Barcelona: Graó.

Prats, J., \& Santacana, J. (2011). Enseñar a pensar históricamente: la clase como simulación de la investigación histórica. En Didáctica de la Geografía y la Historia (Vol. II, pp. 6787). Barcelona: Graó.

Prieto Prieto, J. A., Gómez Carrasco, C. J., \& Miralles Martínez, P. (2013). El uso de fuentes primarias en el aula y el desarrollo del pensamiento histórico y social. Una experiencia en Bachillerato. Clío, 39. Recuperado de http://clio.rediris.es/n39/articulos/historiasocial/PrietoGomezMiralles.pdf

Reventós Santamaría, F. (1983). El fundamento de la metodología comparativa en educación. Educar, 3, 61-75.

Rogers, R. (Ed.). (2011). An introduction to critical discourse analysis in education (Second Edition). New York: Routledge, Taylor \& Francis Group. 
Ruiz Berrio, J. (2007). El adoctrinamiento de los niños españoles mediante las imágenes de los libros de historia en la primera mitad del siglo XX. En J.-L. Guereña (Ed.), Image et transmission des Savoirs dans les Mondes Hispaniques et Hispano-Américains (pp. 415424). Tours-France: CIREMIA.

Sáez Rosenkranz, I. (2016). Análisis de las actividades en libros de texto de Historia, Geografía y Ciencias Sociales de educación básica en Chile (Tesis doctoral). Universidad de Barcelona, Barcelona.

Sáiz Serrano, J. (2014). Fuentes históricas y libros de texto en secundaria: una oportunidad perdida para enseñar competencias de pensamiento histórico. ENSAYOS, Revista de la Facultad de Educación de Albacete, 29(1), 87-99.

Sáiz Serrano, J., \& Colomer, J. C. (2014). ¿Se enseña pensamiento histórico en libros de texto de Educación Primaria? Análisis de actividades de historia para alumnos de 10-12 años de edad. CLío. History and History teaching, (40), 1-19.

Salazar-Jiménez, R., Barriga-Ubed, E., \& Ametller-López, Á. (2015). El aula como laboratorio de análisis histórico: el nacimiento del fascismo en Europa. REIRE. Revista d'Innovació i Recerca en Educació, 8(2), 94-115. https://doi.org/10.1344/reire2015.8.2826

Seixas, P., \& Morton, T. (2013). The Big Six Historical Thinking Concepts. Toronto: Nelson Education.

Toledo Jofré, M. I., Magendzo Kolstrein, A., Gutiérrez Gianellad, V., Iglesias Segura, R., \& López-Facal, R. (2015). Enseñanza de «temas controversiales» en el curso de historia, desde la perspectiva de los estudiantes chilenos. Revista de Estudios Sociales, 35(52), 119-133. https://doi.org/10.7440/res52.2015.08

Valls, R. (2007a). Historiografía Escolar Española: Siglo XIX-XXI. Madrid: UNED.

Valls, R. (2007b). Las imágenes en los manuales escolares de historia y las dificultades de su uso didáctico. Clío \& asociados, 11, 11-23.

Viñao Frago, A. (2008). La escuela y la escolaridad como objetos históricos. Facetas y problemas de la historia de la educación. Historia da Educação, 12(25), 9-54.

Williams, R. (1981). Sociología de la cultura. Barcelona: Paidós. 